\title{
Clinical lead poisoning in England: an analysis of routine sources of data
} Paul Elliott, Richard Arnold, Donald Barltrop, Iain Thornton, Ivan M House,
John A Henry

\begin{abstract}
Objective-To examine the occurrence of clinical lead poisoning in England based on routine sources of data.

Methods-Three routine data sources were examined, over different periods according to availability of data: $(a)$ mortality for England, 1981-96; (b) hospital episode statistics data for England, for the 3 years 1 April 1992-31 March 1995; (c) statutory returns to the Health and Safety Executive under the reporting of injuries, diseases, and dangerous occurrences regulations (RIDDOR), also for the period 1 April 1992-31 March 1995. Also, analyses of blood lead concentrations carried out by the Medical Toxicology Unit, Guy's and St Thomas' Hospital Trust in London during the period 1 January 1991-31 December 1997 were examined. The analyses were performed both for industrial screening purposes and in response to clinicians' requests where lead poisoning was suspected. This is one of several laboratories carrying out such analyses in the United Kingdom.
\end{abstract}

Results-One death, of a 2 year old girl, was coded to lead poisoning in England during 1981-96. Analysis of hospital episode statistics data identified 83 hospital cases (124 admissions) over 3 years with any mention of lead poisoning, excluding two with admissions dating from 1965 and 1969. For these 83 cases the median hospital stay per admission was 3 days (range 0-115 days). Five were coded as having received intravenous treatment. Further clinical details of these cases beyond what is routinely recorded on the hospital episode statistics database were not available, except for blood lead concentrations in cases also identified on the Medical Toxicology Unit database. Eighteen cases $(22 \%)$ were below 5 years of age of whom $10(56 \%)$ came from the most deprived quintile of electoral wards. There was evidence to suggest spatial clustering of cases $(p=0.02)$. Six occupational cases were reported under RIDDOR in England during the period of study, two of whom were identified on the hospital episode statistics database. One further occupational case was identified on hospital episode statistics. Blood lead analyses for 4424 people carried out by the Medical Toxicology Unit (estimated at about $5 \%$ of such analyses in England over 7 years) found that among 547 children aged 0-4, 45
(8.2\%) had a blood lead concentration in excess of $25 \mu \mathrm{g} / \mathrm{dl}$, the action level in the United Kingdom for investigation, or removal of environmental sources of lead. At all ages, there were $419(9.5 \%)$ such people, including 106 adults with no mention of industrial exposure.

Conclusions-Both mortality and hospital admission ascribed to lead poisoning in England are rare, but cases continue to occur and some, at least, seem to be associated with considerable morbidity. Lead poisoning was confirmed as a probable cause of clinical signs and symptoms in only a small proportion of those in whom a blood lead concentration was requested. Where indicated, appropriate remedial action for the safe removal of environmental sources of lead should be taken. (Occup Environ Med 1999;56:820-824)

Keywords: lead; poisoning

Lead is a well known environmental and industrial toxin which may have permanent and possibly fatal consequences, especially in young children. ${ }^{1}$ There have been large falls in both environmental and blood lead concentrations in the United Kingdom over the past 10-15 years, ${ }^{23}$ reflecting reduced use of leaded paints, improved industrial hygiene, and increased use of unleaded petrol, but no recent analysis of the occurrence of clinical lead poisoning - that is poisoning severe enough to cause symptoms - is available. We present here an analysis of routine data on mortality and hospital admissions attributed to lead poisoning in England and on occupational cases of lead poisoning. We also examine blood lead results from a large toxicological referral centre. The aim was to provide an up to date assessment of clinical lead poisoning in England based on routine sources of data.

\section{Methods}

Three sources of routine data were examined, over different periods according to availability: (a) mortality data for England, 1981-96; (b) hospital episode statistics data for England (excluding maternal, neonatal, and psychiatric admissions) for the three years 1 April 1992-31 March 1995; both are based on the postcoded health database held by the Small Area Health Statistics Unit ${ }^{4}$; and (c) statutory returns to the Health and Safety Executive under the Reporting of Injuries, Diseases and Dangerous Occurrences Regulations (RIDDOR), ${ }^{5}$ also for the period 1 April 1992-31 March 1995. 


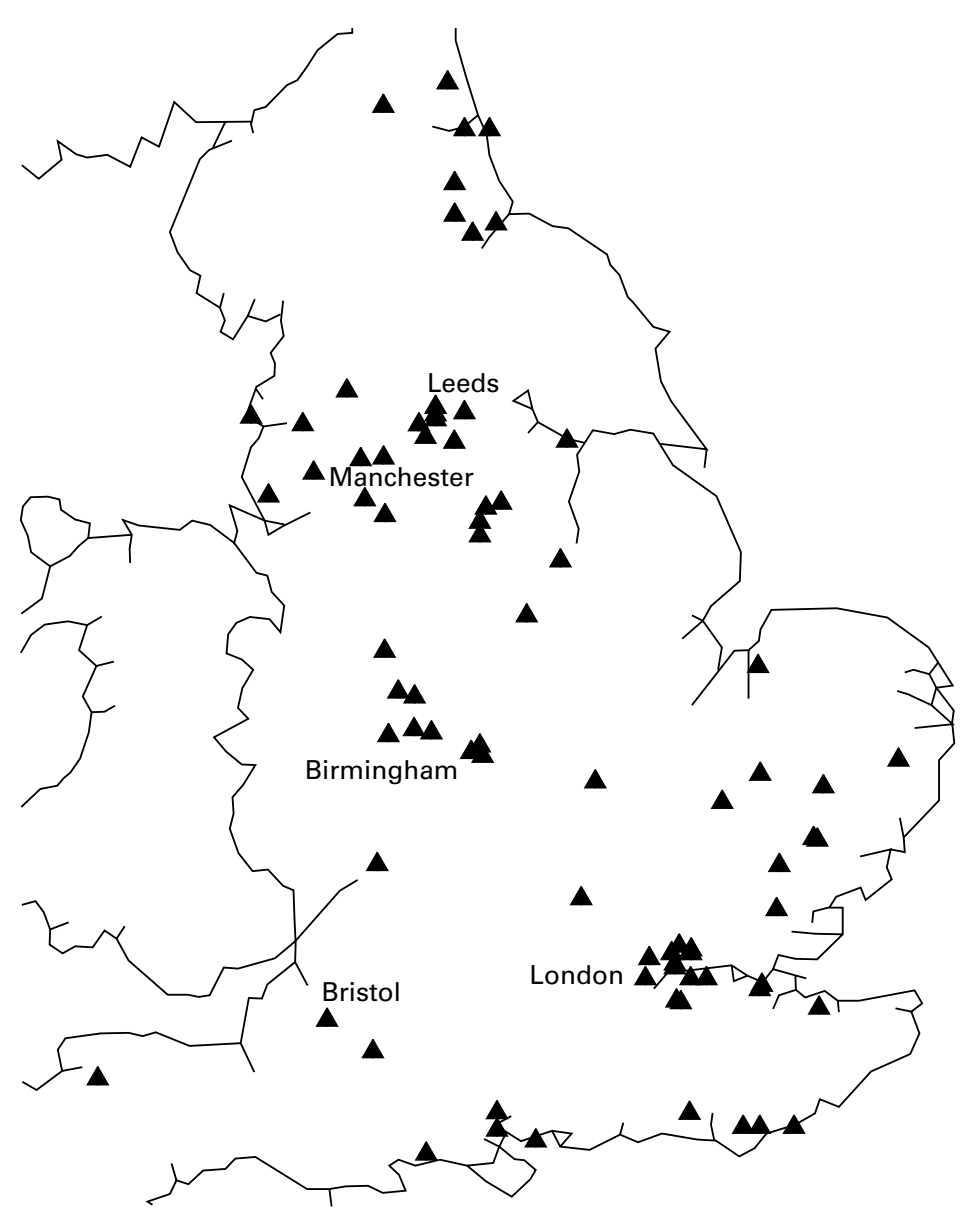

Figure 1 Geographical distribution of the place of residence of 83 cases of lead poisoning admitted to hospital in England from 1 April 1992-31 March 1995.

Also, analyses of blood lead concentrations (whole blood) were examined with graphite furnace atomic absorption spectrometry, carried out by the Medical Toxicology Unit, Guy's and St Thomas' Hospital Trust in London during the period 1 January 1991-31 December 1997. The analyses were done both for industrial screening purposes and in response to clinicians' requests where lead poisoning was suspected, and represent recent exposure to lead. This is one of several laboratories carrying out such analyses in the United Kingdom. The blood lead analyses are performed in response to laboratory request forms, but the clinical indication for the request is not always filled out on the form. However, requests for the purposes of industrial screening are identified. A wide range of industry is covered to include small businesses involved in scrap metal recovery, melting down of batteries, and similar activities.

For the mortality and hospital episode statistics data, lead poisoning was defined by the international classification of diseases 9 th revision (ICD-9) code 984 (toxic effect of lead and its compounds including fumes) and by two external (E) codes: 8660 (accidental poisoning by other and unspecified solid and liquid substances-lead and its compounds and fumes) and 8615 (accidental poisoning by cleansing and polishing agents, disinfectants, paints, and varnishes - lead paints). Cases were located to their place of residence by their postcode (10-100 $\mathrm{m}$ resolution) and hence to their 1991 electoral ward. A deprivation score was assigned to each ward based on quintiles of the distribution of the Carstairs index in England. ${ }^{6}$ Analysis of the mortality data was based on the coding of underlying cause of death from 1981-92 and included secondary causes from 1993-6.

Analysis of hospital episode statistics data was based on mention of lead poisoning in any one of the seven diagnostic code fields. Further clinical details of the cases beyond what is routinely recorded on the hospital episode statistics database were not available, except for blood lead concentrations in cases also identified on the Medical Toxicology Unit database. Repeated admissions to hospital for the same person were identified by scrutiny of date of birth, sex, and postcode. Tests of spatial clustering $^{7}$ were carried out at electoral ward level based on the distribution of cases and populations at ages $0-4$ years and $\geqslant 5$ years. Briefly, wards were aggregated in the neighbourhood of each case until the expected number of cases was equal to or greater than an integer $\mathrm{k}$. The sum of differences between observed and expected numbers of cases in all such neighbourhoods gave a global measure of clustering, with significance obtained by comparison, for each value of $k$, with 999 simulations of the data. Overlapping neighbourhoods with a significant $(p<0.05)$ excess of observed compared with expected numbers of cases were aggregated and labelled as possible clusters. Theoretically, this analysis may not be fully independent of an analysis of the incidence of lead poisoning by deprivation, to the extent that any geographical clustering of cases may reflect the tendency for cases to occur in deprived areas, and for deprived areas to be clumped together.

\section{Results}

\section{MORTALITY}

One death (in 1987) of a 2 year old girl was coded to lead poisoning in England during 1981-96. The death certificate recorded lead encephalopathy and misadventure was noted. Place of birth on the Indian subcontinent was also noted. Further enquiry of the physicians that attended this case showed that she had arrived in the United Kingdom at the age of 6 months. She presented at the age of 2 with a history of vomiting for 8-10 days. The day after admission she deteriorated, with low blood pressure, hypotonia, lethargy, neck stiffness, extensor plantar reflexes, and papilloedema. A diagnosis of lead encephalopathy was suggested by the finding of marked basophilic stippling of the erythrocytes, a hypochromic microcytic anaemia with haemoglobin of 7.1 $\mathrm{g} / \mathrm{dl}$, and the appearance of radio-opaque flakes distributed throughout the gut on abdominal $x$ ray film. Her initial blood lead concentration was $352 \mu \mathrm{g} / \mathrm{dl}$. This decreased progressively to $102 \mu \mathrm{g} / \mathrm{dl}$ over 48 hours with intramuscular dimercaprol and intravenous calcium EDTA treatment, but without clinical improvement. A history of pica for domestic paint was found 
Table 1 Demographic characteristics of 83 cases of lead poisoning admitted to hospital in England, 1 April 1992 to 31 March 1995

\begin{tabular}{|c|c|c|c|}
\hline & \multicolumn{3}{|c|}{ Cases (n (\%)) } \\
\hline & Total & Males & Deprived $t$ \\
\hline \multicolumn{4}{|l|}{ Age: } \\
\hline $0-4$ & 18 & $11(61)$ & $10(56)^{\star \star \star}$ \\
\hline $5-14$ & 9 & $6(67)$ & $3(33)$ \\
\hline$\geqslant 15$ & 56 & $43(77)^{\star \star \star \star}$ & $16(29)^{\star \star}$ \\
\hline Total & 83 & $60(72)$ & $29(35)$ \\
\hline
\end{tabular}

${ }^{\star \star} \mathrm{p}=0.01 ;{ }^{\star \star \star} \mathrm{p}<0.001$.

tWard of residence in the most deprived quintile by Carstairs score.

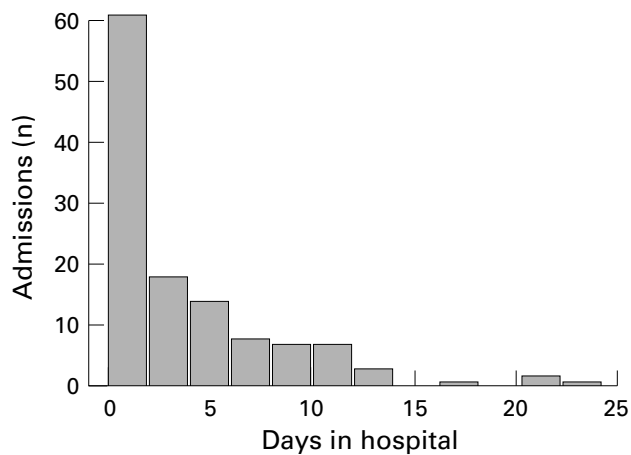

Figure 2 Hospital episode statistics 1992-3 to 1994-5, admissions with mention of lead poisoning (two stays of 81 and 115 days not shown).

which was shared by two of her three cousins. Investigation of the family showed low blood lead values in her mother and father $(6 \mu \mathrm{g} / \mathrm{dl}$ and $8 \mu \mathrm{g} / \mathrm{dl}$ respectively). Her elder sister aged 5 years had a minimal increase of blood lead $(22 \mu \mathrm{g} / \mathrm{dl})$. Screening of children in her uncle's family showed two children with increased values of $66 \mu \mathrm{g} / \mathrm{dl}$ and $29 \mu \mathrm{g} / \mathrm{dl}$. The clinical notes report that a sample of paint had been analysed and found to contain $14 \%$ lead.

HOSPITAL EPISODE STATISTICS (HES)

Analysis of hospital episode statistics data over 3 years identified 85 cases with any mention of lead in the discharge diagnosis coding. Two were long stay cases with admissions dating from 1965 and 1969, and were excluded from further analysis. They had been admitted at ages 15 and 4 with primary diagnoses of "moderate mental retardation" and "severe mental retardation", respectively; both cases also had a diagnosis of epilepsy.

Table 2 People $(n(\%))$ by age and blood lead concentration * for analyses performed by the Medical Toxicology Unit, Guy's and St Thomas'Hospital Trust, 1 fanuary 1991 to 31 December 1997

\begin{tabular}{|c|c|c|c|c|c|c|}
\hline & \multicolumn{5}{|c|}{ Blood lead ( $\mu g / d l)$} & \multirow[b]{2}{*}{ Total } \\
\hline & $0-10.0$ & $10.1-25.0$ & $25.1-40.0$ & $40.1-70.0$ & $\geqslant 70.1$ & \\
\hline \multicolumn{7}{|l|}{ Age: } \\
\hline $0-4$ & $424(78)$ & $78(14)$ & $21(4)$ & 17 (3) & $7(1)$ & 547 \\
\hline $5-14$ & $516(91)$ & $41(7)$ & $6(1)$ & $3(1)$ & $2(0)$ & 568 \\
\hline$\geqslant 15$ & $2153(69)$ & $595(19)$ & $212(7)$ & $122(4)$ & $20(1)$ & $3102 \dagger$ \\
\hline Not known & $172(83)$ & $26(13)$ & $5(2)$ & $4(2)$ & 0 & 207 \\
\hline Total & 3265 & 740 & 244 & 146 & 29 & 4424 \\
\hline
\end{tabular}

${ }^{\star}$ For industrial screening, the highest blood lead concentration was used; for all other people, results of the first blood lead analysis was used. Results for two people known to be from Scotland have been excluded.

†Includes numbers of people where mention was made of industrial exposure, as follows: $0-10.0$ $\mu \mathrm{g} / \mathrm{dl}: 830 ; 10.1-25.0$ : 384; 25.1-40.0: $152 ; 40.1-70.0$ : 89; 70.1+: 7 ; total: 1462 .
The geographical distribution of the remaining 83 cases (124 admissions) is shown in figure 1 . Median age was 25 years (range 10 months to 75 years); 60 (72\%) were males. Eighteen cases $(22 \%)$ were below 5 years of age of whom $10(56 \%)$ came from the most deprived quintile of wards $(\mathrm{p}<0.001$, table 1$)$. Median hospital stay per admission was 3 days (range 0-115 days, fig 2); including readmissions, it was 3 days per patient (range 0-196 days). Five cases were recorded as having had a "continuous infusion of a therapeutic substance", of whom two were under 5 years of age. For 53 of the 83 cases $(64 \%)$, lead poisoning was given as the primary diagnosis.

There was evidence to suggest spatial clustering, $\mathrm{p}=0.02$ from the global test at $\mathrm{k}=2$, 3 , and 4. Two groupings persisted over several scales, for different values of $\mathrm{k}$. The strongest comprised four neighbourhoods with significance $\mathrm{p}<0.01$ concentrated in West Yorkshire. It was found at scales $k=1,2,3$, and 4 . Ten cases (eight males, seven adults $<50$ years) formed the core of the cluster, over an area of about $14 \mathrm{~km}$ in radius. A second, much weaker, grouping was found elsewhere at scales $k=2$ and 3 only, with none of the neighbourhoods significant at $\mathrm{p}<0.01$.

\section{BLOOD LEAD ANALYSES}

Results of blood lead analyses carried out by the Medical Toxicology Unit are shown in table 2 . The cut off points for blood lead concentrations were chosen to represent clinically relevant values (see discussion). Among 547 children aged $0-4,45(8.2 \%)$ had a blood lead concentration in excess of $25 \mu \mathrm{g} / \mathrm{dl}$ (maximum value 320). Measurements were carried out on 4424 people at all ages, including 3102 adults $(\geqslant 15$ years), of whom there was no mention of industrial exposure for 1640 (53\% of adults). Four hundred and nineteen people $(9.5 \%)$ of all ages had blood lead concentrations $>25$ $\mu \mathrm{g} / \mathrm{dl}$ (maximum value 657 ), with no mention of industrial exposure for 106 of the 354 adults.

A comparison was made between data recorded on the Medical Toxicology Unit database and those on the hospital episode statistics database. One thousand four hundred and twenty two people had blood lead measured during the period 1 April 1992-31 March 1995: 193 at ages 0-4 years; 143 at $5-14 ; 80$ with age unknown; and there were 1006 adults, 444 and 562 with and without mention of industrial exposure, respectively. Eight of the children at ages $0-4$ and two at ages 5-14 had blood lead values above 40 $\mu \mathrm{g} / \mathrm{dl}$, of whom five (all at ages $0-4$ ) were identified on the hospital episode statistics database. Seventeen adults had blood lead concentrations $>60 \mu \mathrm{g} / \mathrm{dl}$, of whom four were identified on the hospital episode statistics database. Thus in total, nine out of 1422 people $(0.6 \%)$ were identified as hospital admissions.

\section{OCCUPATIONAL CASES}

Six cases were reported to the Health and Safety Executive under RIDDOR in England 
during the period 1 April 1992-31 March $1995 .{ }^{5}$ Dates of birth were made available to us (by the Health and Safety Executive) and two (both male, aged 25 and 57) were identified on the hospital episode statistics database $(2.4 \%$ of the hospital episode statistics cases). An additional industrial case with an extremely high blood lead concentration $(657 \mu \mathrm{g} / \mathrm{dl})$ was identified on hospital episode statistics from the comparison with the Medical Toxicology Unit database.

\section{Discussion}

This study is the first comprehensive overview of mortality and morbidity requiring hospital admission from lead poisoning in England. We found one death attributable to lead poisoning over a 16 year period, in a 2 year old girl with a history of pica for paint. There were 83 cases identified as having had one or more hospital admissions over 3 years (28 cases a year), giving an annual rate of 5.72 cases per 10 million population at all ages, and 18.5 per 10 million at ages $0-4$. Five cases were recorded as having had therapeutic infusions.

These data are derived from death certificates and the routine reporting of hospital episode statistics, and as such are subject to errors, including both false positive and false negative cases. The death occurred in a child known to us and was a well documented case. It is possible, however, that other deaths may have been missed, for example, from an undiagnosed encephalopathy where lead poisoning was unsuspected. The one death over a 16 year period contrasts with the situation in the early 1970s when around two deaths a year in children were ascribed to lead poisoning, ${ }^{8}$ and may reflect the fact that lead is no longer used in paints.

For hospital admissions, we were dependent on routine coding of discharges which are prone to diagnostic, coding, and transcription errors. ${ }^{9}$ Further clinical details of the cases beyond the data routinely recorded on the hospital episode statistics database were unavailable for review, except where blood lead concentrations were available from comparison with the Medical Toxicology Unit database. For certain well defined conditions - such as asthma and diabetes - the hospital episode statistics seem to produce data with high reproducibility, at least for primary diagnosis and three digit ICD code. ${ }^{9}$ The quality of hospital episode statistics data for recording rare events - such as heavy metal poisoning-is however unknown. As the diagnosis of lead poisoning depends on clinical suspicion and on a highly specific test-namely blood lead concentration - it seems unlikely that many false positive cases were included, unless there were errors in coding.

The median hospital stay was 3 days. Duration of stay was $0-2$ days for 61 of 124 admissions among the 83 cases (figure 2 ). It is therefore likely that many cases were mild, and in some cases an increased blood lead value may have been an incidental finding. On the other hand, hospital stays of up to 115 days were recorded; for 21 admissions, stays of 10 days or more were recorded. The five cases recorded as requiring intravenous treatment, presumably chelation treatment, may be an underestimate if (as seems likely) clinical procedures are not captured well in the routine data. It is probable also that some cases of lead poisoning were missed (false negatives). For example, blood lead concentrations will not necessarily be sought routinely in children with the nonspecific features that occur in the preencephalopathic phase of lead toxicity.

The highest admission rate was found among young children $<5$ years of age. At this age, ingestion of leaded paint and lead rich house dust is the major source of exposure, particularly in older homes, ${ }^{10}$ leading to possible severe or fatal lead poisoning. ${ }^{11}$ Variations in dietary intake by virtue of social class, ethnic group, and cultural background may modify lead absorption and toxicity. ${ }^{1}$ At ages $0-4$, more than half the hospital admissions were found in the most deprived quintile of areas.

As well as the 83 cases, two further long stay cases with diagnoses of mental retardation, epilepsy, and mention of lead were identified. It was not possible to determine from the routine data when the diagnoses of lead poisoning had been made, and whether these cases reflected lead exposure-for example, from pica-in children with previous disabilities, or disability occurring as a result of lead exposure.

We found evidence for a possible cluster of hospital admissions for lead poisoning over a $14 \mathrm{~km}$ radius in West Yorkshire. Eight of the 10 core cases were males, seven aged 20-50 years. Although this suggests a possible occupational cause, we are unaware of any obvious occupational source in the area. None of these cases had been identified in the statutory returns to the Health and Safety Executive. However, as the cases were identified by place of residence and not by place of work, it remains possible that an occupational cause of the cluster may have been missed. The area is monitored for lead concentrations in the water supply. In 1994, 3.5\% of samples monitored by Yorkshire Water exceeded the United Kingdom standard of $50 \mu \mathrm{g} / 1$ in any one sample. ${ }^{12}$

Six occupational cases were notified under RIDDOR in England during 3 years, and we identified an additional occupational case, with a high blood lead concentration, who was admitted to hospital. The most recently available statistics from the blood lead screening programme in industry, for 1996-7, showed 14831 men and 897 women under medical surveillance, of whom 116 and 1 , respectively, had blood lead values $>70 \mu \mathrm{g} / \mathrm{dl}$, (the suspension level then in force under the Control of Lead at Work Regulations 1980, except for women of reproductive capacity, whose suspension level was $40 \mu \mathrm{g} / \mathrm{dl} ; 48$ men and three women were suspended ${ }^{5}$ ). The suspension concentrations of 70 and $40 \mu \mathrm{g} / \mathrm{dl}$ were reduced to 60 and $30 \mu \mathrm{g} / \mathrm{dl}$ respectively by the Control of Lead at Work Regulations 1998 which came into force in April 1998. Those regulations also introduced a new suspension concentration of $50 \mu \mathrm{g} / \mathrm{dl}$ for young people aged $<18$ years. 
Clinical effects are not usually associated with blood lead concentrations below about 40 $\mu \mathrm{g} / \mathrm{dl}$ in children, and at somewhat higher values in adults, although at lower concentrations, down to $10 \mu \mathrm{g} / \mathrm{dl}$ or even below, there is epidemiological evidence of small subclinical effects, particularly on neuropsychological development in children and (less persuasively) on blood pressure in adults. ${ }^{13-16}$ In 1982, The United Kingdom Department of Health and Social Security advised that "where a personparticularly a child-is confirmed as having a blood lead of $>25 \mu \mathrm{g} / \mathrm{dl}$, his or her environment should be investigated for sources of lead and steps taken to reduce exposure". ${ }^{17}$ The current United Kingdom government policy is to pursue measures to reduce blood concentrations to $<10 \mu \mathrm{g} / \mathrm{dl}$.

The blood lead analyses carried out by the Medical Toxicology Unit identified 45 people over a 7 year period with values $>25 \mu \mathrm{g} / \mathrm{dl}$ at ages $0-4$ and 419 at all ages-that is, around 6.5 and 60 per year respectively - there was no mention of industrial exposure among adults in 106 of these requests - that is, about 15 per year-although the information volunteered to the laboratory may be incomplete. Apart from industrial screening, the commonest clinical indications for the blood lead analyses were abdominal pain, developmental delay, and anaemia. Over a 3 year period, $<1 \%$ of people on the Medical Toxicology Unit database were identified as hospital admissions in the hospital episode statistics database.

We estimate that the Medical Toxicology Unit carries out about $5 \%$ of all blood lead examinations in England, but only around 1\% of those done on industrial workers under medical surveillance. ${ }^{5}$ Many of the examinations were done on clinical suspicion to rule out the possibility of lead toxicity, which explains why the pick up rate was low. As the data from the Medical Toxicology Unit do not give national coverage and may not be representative, especially as they relate only to people where clinical suspicion led to a request for blood lead analysis, data from population surveys are required to assess blood lead concentrations in the community. Recent population based surveys based on small numbers of people found 2/586 children aged 2.5 years $^{18}$ and $11 / 6517$ adults aged $\geqslant 16$ years $^{19}$ with blood lead values $>25 \mu \mathrm{g} / \mathrm{dl}$, with the vast majority having concentrations $<10 \mu \mathrm{g} / \mathrm{dl}^{2}{ }^{2}$

In conclusion, although both mortality and hospital admission ascribed to lead poisoning in England are rare, at least some of the hospital admissions seem to be associated with considerable morbidity. In theory such cases of lead poisoning should be preventable. The blood lead results indicate that lead poisoning is a probable cause of clinical signs and symptoms in only a small proportion of those in whom the diagnosis is suspected. Where indicated, appropriate remedial action for the safe removal of environmental sources of lead should be taken.

The Small Area Health Statistics Unit is funded by a grant from the Department of Health, Department of the Environment, Health and Safety Executive, Scottish Office Home and Health Department, Welsh Office, and Northern Ireland Department of Health and Social Services. We thank the Office for National Statistics and the Department of Health for making the postcoded mortality and Hospital Episode Statistics data available to us, and the Health and Safety Executive for providing details of RIDDOR cases. PE and RA were supported by an equipment grant from the Wellcome Trust (0455051/Z/95/Z), and DB is supported by the Westminster Children's Research Trust. This work uses data provided with the support of the Economic and Social Research Council and Joint Information Economic and Social Research Council and Joint Information Services Committee, and census and boundary material which are copyright of the Crown, the Post Office and the ED-LINE Consortium. The views expressed in this paper are those of the
authors and not necessarily those of the funding departments.

1 Chisolm JJ, Barltrop D. Recognition and management of children with increased lead absorption. Arch Dis Child 1979;54:249-62.

2 Delves HT, Diaper SJ, Oppert S, et al. Blood lead concentrations in United Kingdom have fallen substanconcentrations in United Kingdom have

3 Wang Y, Thornton I, Farago M. Changes in lead concentrations in the home environment in Birmingham, England over the period 1984-96. Sci Total Environ 1997;207:149 56.

4 Elliott P, Westlake AJ, Kleinschmidt I, et al. The Small Area Health Statistics Unit: a national facility for investigating health around point sources of environmental pollution in the United Kingdom. $\mathcal{F}$ Epidemiol Community Health 1992; 46:345-9.

5 Health and Safety Commission. Health and Safety Statistics 1997-8. Sudbury: HSE Books, 1998.

6 Carstairs V. Deprivation indices: their interpretation and use in relation to health. $\mathcal{F}$ Epidemiol Community Health 1995;49(suppl 2):S3-8.

7 Cuzick J, Edwards R. Tests for spatial clustering in heterogeneous populations. Fournal of the Royal Statistical Society B 1990;52:73-104.

8 Department of the Environment Central Unit on Environmental Pollution. Lead in the environment and its significance to man. London: HMSO, 1974. (Pollution Paper No 2.)

9 Dixon J, Sanderson C, Elliott P, et al. Estimating the accuracy of clinical coding on hospital episode statistics in North West Thames Region. F Public Health Med 1998;20: 63-9.

10 Hunt A, Johnson DL, Watt JM, et al. Characterising the sources of particulate lead in house dust by automated scanning electron microscopy. Environmental Science and Technology 1992; 26: 1513-1523.

11 Schirmer J, Anderson HA, Saryan LA. Fatal pediatric poisoning from leaded paint-Wisconsin, 1990. MMWR Morb Mortal Wkly Rep 1991;40:193-5.

12 Drinking Water 1994. A report by the chief inspector of drinking water. London: HMSO, 1994.

13 World Health Organization. Inorganic lead. WHO Environmental Health Criteria 165. Geneva: WHO, 1995.

14 Pocock SJ, Smith M, Baghurst P. Environmental lead and children's intelligence: a systematic review of the epidemiochildren's intelligence: a systematic review
logical evidence. $B M \mathscr{f}$ 1994;309:1189-97.

15 Baghurst PA, McMichjael AJ, Wigg NR, et al. Life-long exposure to environmental lead and children's intelligence at age seven: the Port Pirie cohort study. $N$ Engl $f \mathrm{Med}$ at age seven: the Port

16 Fulton M, Raab G, Thomson G, et al. Influence of blood lead on the ability and attainment of children in Edinburgh. Lancet 1987; i: 1221-6.

7 Department of the Environment and Welsh Office. Lead in the environment. London: The Stationery Office, 1982. (Circular 22/82.)

18 Golding J, Smith M, Delves T, et al. The ALSPAC study on lead in children. In: Gompertz D, ed. IEH report on recent UK blood lead surveys (report R9). Leicester: Institute for Environment and Health, 1998.

19 Primatesta P, Dong W, Bost NR, et al. Survey of blood lead levels in the population in England 1995. In: Gompertz D, ed. IEH report on recent UK blood lead surveys (report $R 9)$. Leicester: Institute for Environment and Health, 1998. 